\title{
Fast Pyrolysis Biomass Oil as the Substitute of Phenol for the Synthesis of Resol Resin as Wood Adhesive
}

\author{
Fu-xia SUN \\ School of Chemical Engineering, \\ Taishan Medical University, \\ China, 271016 \\ Hong SUN \\ School of Chemical Engineering, \\ Taishan Medical University, \\ China, 271016
}

\author{
Fang KONG \\ School of Chemical Engineering, \\ Taishan Medical University, \\ China, 271016 \\ Zhe-hui WANG* \\ School of Chemical Engineering, \\ Taishan Medical University, \\ China, 271016 \\ E-mail: wangzh@tsmc.edu.cn
}

\begin{abstract}
The bio-oil from fast pyroysis of cornstalks was used as the substitute for phenol to synthesize resol resins as aln ideal candidate of wood adhesives. The effects of formaldehyde/phenol (F/P) molar ratios and bio-oil/phenol $(\mathrm{O} / \mathrm{P})$ weight ratios on rheology, thermal cure, thermal resistance and adhesion of plywoods were investigated. With an increase in bio-oil addition, the gel time became longer, and the thermal cure exothermic temperature shifted slightly higher. It was found that the bio-resol resin with bio-oil/phenol=1/2(wt) and $F / P=1.5(\mathrm{~mol})$ had the best comprehensive properties. The plywoods pr $^{\circ} \mathrm{C}$ essed with bio-resol adhesives were consistent with the plywood standards of E0 and type $\mathrm{I}^{*}$.
\end{abstract}

Keywords-Bio-oil; Phenol; Substitute; Thermosets; Crosslinking; Wood adhesives

\section{INTRODUCTION}

Biomass is well known as one of the key renewable resources of the future generation, which represents $14 \%$ of the total global energy supply [1,2]. Based on its immense potential and economic viability, biomass has already been a large source for the production of bio-fuels and various materials. As reported by D.O.Hall, estimates show that biomass contribution will represent $17-30 \%$ of total energy requirement up to 2050 in Europe [3]. Unfortunately, agricultural and forestry lignocellulosic waste is mostly disposed by means of burning or land filling.

Nowadays, there is a growing interest in developing lignocellulosic biomass in the applications of phenolic resins. Phenolic resin was made from starch which was used in place of phenol in a preliminary study [4]. Also, it is widely accepted that lignin played an important role in phenolic resin preparation, considering the ideal properties of lignin modified phenolic resins and the vast availability of ligin-containing renewable feedstocks [5]. However, because of the biological toxicity to humans, lignin is included in the USEPA list of priority pollutants [6]. Due to this, liquefying lignocellulosic wastes into liquid products for the resin synthesis proved to be more promising and necessary.

Compared with direct liquefaction of lignocellulosic biomass in hot compressed or supercritical solvents $[7,8]$, fast pyrolysis (including vacuum fast pyrolysis, plasma assistant fast pysolysis, flash pysolysis, etc) was one more effective method to get bio-oils ideal for the production of phenolic resins $[9,10,11]$ : no use of phenol or ethanol solvents, efficient cost, facile operation for large scale production, low molecules and ideal components (chemicals rich in phenolic compounds, and viscosity suitable for resin production).

In the literatures reported, it was believed that the amount of bio-oil to replace phenol was not higher than $1 / 3$ so as not to significantly degrade resin properties [12]. But it is important to further understand the tendency in a wide range of replace ratios, if the bio-oil resols will find promising applications in adhesive for ply-woods, matrix for composites, and carbon precursor for high temperature resistant materials, etc.*

In this work, it was studied that the synthesis and properties of bio-oil modified resol type phenolic resins. The purpose of the study is to study the effect of the substitute amount on the resin processability and material properties, and to understand the feasibility of comparable high levels of phenol replacement in the formulation of bio-oil modified resol resins. Also the performances of plywoods with bio-oil formulated resol resins as adhensives were investigated.

\section{MATERIALS AND METHODS}

\section{A. Materials}

Phenol (>99\%, AR), formaldehyde (37 wt\% aqueous solution, AR), and sodium hydroxide (AR) were obtained from Tianjin Chemical Reagent, Ltd, China. Bio-oil of cornstalks by fast pyrolysis is donated by one local company. Other materials were all commercial products, and usedas received. 


\section{B. The Pretreatment of Bio-oil before Synthesis of Bio-} resols

Before use for the synthesis of phenolic resol resins, the bio-oil was pretreated to satisfy the requirments of phenolic resin by removing the water soluables. The bio-oil was rinsed with deionized water for 3 times at $50-60^{\circ} \mathrm{C}$, then distilled by rotary evaporation. The element components of the dried bio-oil was analyzed, and listed in Table 1.

TABLE 1.ELEMENT ANALYSIS OF THE PURIFIED BIO-OIL

\begin{tabular}{llll}
\hline Element & Carbon & Hydrogen & Oxygen \\
\hline Amount (wt\%) & 55.9 & 7.4 & 36.7 \\
\hline
\end{tabular}

\section{The Synthesis of Bio-oil Resol Resins}

In the synthesis of bio-oil resol resins, the reaction vessel of a three-neck flask matched with a condenser, a thermometer and a dropping funnel was heated in oil bath. Under magnetic stirring, phenol and bio-oil were charged according to the pre-set amounts with varying ratios, and the basic catalyst of sodium hydoxide (1\% based on the amount of phenol and bio-oil) was then added. The calculated amount of formaldehyde was dropped slowly for 30-40 min at $85-90^{\circ} \mathrm{C}$. After reaction at about $100{ }^{\circ} \mathrm{C}$ for $2 \mathrm{~h}$, a darkbrown and viscous resin was recovered by dumping the upper water. The resol resins were stored in fridge to prevent the self-curing at ambient conditions. A series of bio-resol resins with varying bio-oil/phenol ratios and varying formaldehyde/phenol ratios was prepared in the above procedure.

\section{Thermal Cure}

The cornstalk-derived bio-oil resol resins (as well as the conventional resol as comparison) were cured in convection oven according to the following procedure: RT-180 ${ }^{\circ} \mathrm{C}$ at $10^{\circ} \mathrm{C} / \mathrm{min}, 180^{\circ} \mathrm{C} 2 \mathrm{~h}$, cool down naturally.

\section{E. Pylwoods Preparation}

The bio-oil resol resins (bio-oil/phenol of 1/4, 1/2 and 1/1 while $\mathrm{F} / \mathrm{P}$ of 1.5 ; bio-oil/phenol of $1 / 2$ while $\mathrm{F} / \mathrm{P}$ of 1.2 ) and conventional resol resin with $\mathrm{F} / \mathrm{P}$ of 1.5 as comparison were used as adhesives for poplar 5-layer plywoods. The plywoods were hot pressed at $130^{\circ} \mathrm{C}$ for $30 \mathrm{~min}$ with adhesive amount of $150 \mathrm{~g} / \mathrm{m} 2$.

\section{F. Measurements and Instruments}

The viscosity of the bio-resol resins was measured by rotary viscometer (NDJ-1) at ambient temperature. FT-IR measurements were carried out on Nicolet (IS10, USA) for the cured samples of varying bio-reols. DSC spectra were obtained on Diamond DSC (PerkinElmer, USA) in flowing nitrogen atmosphere of $50 \mathrm{~mL} / \mathrm{min}$ at a constant heating rate of $10{ }^{\circ} \mathrm{C} / \mathrm{min}$. Gel time of the bio-resols was measured at $120^{\circ} \mathrm{C}$ on Gel Time Meter (GT-3, Hangzhou Meiya Electronic Incorporation) according to the standard of ASTM D3056-1985. The thermal degradation of the cured resins was examined on TGA (Netzch409PC) at a heating rate of $10^{\circ} \mathrm{C} / \mathrm{min}$ in flowing nitrogen atmosphere of $20 \mathrm{~mL} / \mathrm{min}$. The adhension strength was tested for all the plywoods with different resols as per the standard of GB/T 9846-2004 for type I plywood board. The formaldehyde emission was determined according to the above standard.

The purification of bio-oil (fast pyrolysis of cornstalk at $500^{\circ} \mathrm{C}$ under nitrogen flow) was conducted to remove water solubles, the dried purified bio-oil was viscous black liquid. At room temperature, the viscosity of the purified bio-oil was around $10,000 \mathrm{cP}$. So at the polycondensation conditions of resol resin (typical at $80-100{ }^{\circ} \mathrm{C}$ in basic aqueous solution), the liquid bio-oil smoothly joined in the reaction system to form a uniform product.

\section{CONCLUSIONS}

In the synthesis of bio-oil resol resins, varying biooil/phenol ratios and formaldehyde/phenol ratios were adopted. The reaction in the biooil-phenol formaldehyde system was found to proceed readily. The bio-phenols in the bio-oil participated the condensation reaction with formaldehyde in a similar way to phenol. So it would be elucidated that the bio-oil resols are all single component resin, and the bench stability, reliable processability and high properties were guaranteed. This is quite different from the blend resin with biomass as extender additive.

The phenolic resol resins synthesized under alkaline condition generated a variety of hydroxyl cresol because of addition reaction between formaldehyde and phenol. With the ratios of $\mathrm{F} / \mathrm{P}$ molar ratios increased, the fraction of unitary and multivariate phenolic alcohols increased so that the degree of polycondensation was enhanced. Along with the continuous polycondensation reaction, the viscosity of phenolic resol resin increased with the increase of $\mathrm{F} / \mathrm{P}$ molar ratios. The rehology and thermal cure behaviors changed upon variable synthetic conditions. It is critical information for resol industrial applications to learn its process capability.

When the replacement increased (Bio-oil/Phenol ratio increased), for the bio-resols prepared at F/P 1.5 and F/P 1.2, there was a similar trendency of viscosity change. With the introduction of bio-oil into the polymerization, there was a small effect on the viscosity of the final resins. The condensation reactivity of phenol was higher than that of bio-oil, and optimum $\mathrm{O} / \mathrm{P}$ would exist where the phenol and bio-oil was in good match of reaction with formaldehyde. While at $\mathrm{O} / \mathrm{P}$ of $1 / 2$, the viscosity of the resin reached the maximum, implying the reactivity of bio-oil and phenol matched well at this point. While higher replacement was applied, the viscosity of the resin decreased slightly, indicating the lower reactivity of bio-oil. Based on these results, the bio-oil with a smaller replacement $(\mathrm{O} / \mathrm{P}$ at $1 / 2)$ in the resin was the minor reactant, can be regarded as good crosslinking monomer; but the bio-oil with a bigger replacement $(\mathrm{O} / \mathrm{P}$ at $>1 / 1.5)$ was the major reactant, and the low reactivity of bio-oil leads to the slow polycondensation and lower viscosity of the resin.

The bio-oil derived from fast pyrolysis of cornstalks were ideal substitute for phenol to prepare resol resins, and the replacement of phenol by bio-oil was effective even at as high as $50 \%$.

(2) The formaldehyde/phenol (F/P) molar ratios and O/P 
mass ratios had clear effects on rehology, thermal cure activity, thermal resistance and adhesion of plywoods.

(3) While the replacement was increased, the gel time became longer, indicating the retardation of crosslinking polymerization of the existence of unavoidable amount of bio-oil in the bio-resols.

(4) The bio-resol with bio-oil/phenol=1/2(wt) and $\mathrm{F} / \mathrm{P}=1.5$ (mol) had the best comprehensive properties, while at high substitution levels the bio-resols were still an ideal adhesive for plywoods.

(5) The bio-resol resins were cost-effective and environment-friendly adhesives of type I plywoods.

\section{REFERENCES}

[1] Demirbas A. Progress in Energy and Combustion Science 2005; 31(2): 171-192.

[2] Biomass Research and Development Technical Advisory Committee. Roadmap forBiomass technologies in the U.S. 2002. http://www1.eere.energy.gov/biomass/publications.html.(Accessed 2 March 2014).

[3] Hall DO. Forest Ecology and Management 1997; 91(1): 17-45.

[4] Yoshida C, Okabe K, Yao T, Shiraishi N, Oya A. J Mater Sci 2005; 40(2): 335-339.

[5] KlasnjaB, Kopitovic S.Holz Roh-Werkst1992; 50(7): 282-285.

[6] Puig D, Barceló D. Chromatographia 1995; 40(7-8): 435-444.

[7] Wang M, Leitch M, Xu C. Journal of Industrial and Engineering Chemistry 2009; 15: 870-875.

[8] Alma MH, Basturk MA. Industrial Crops and Products 2006; 24: 171176.

[9] Mohan D, Pittman Jr CU, Steele PH.Energy \& Fuels 2006; 20:848889.

[10] Nakos P, Tsiantzi S, Athanassiadou E. In $\operatorname{Pr}^{\circ} \mathrm{C}$ eedings of the $3^{\text {rd }}$ European wood-based panel symposium; European Panel Federation \& Wilhelm Klauditz Institute: Hanover, Germany, 2001.

[11] Xu J, Jiang J, Kang S. Iran J Chem Chem Eng 2011; 30(1): 83-87.

[12] Effendi A, Gerhauser H,Bridgwate, AV. Renewable and Sustainable Energy Reviews 2008; 2: 2092-2116.

[13] Kissinger HE. Anal Chem 1957; 29: 1702-1709.

[14] Crane LW, Dynes PJ, Kaelble DH. J Polym Sci Part C: Polym Lett Ed 1973;11(8):533-540.

[15] Shen DK, Gu S, Luo KH, Wang SR, Fang MX. Bioresource Technology 2010; 101(15): 6136-6146.

[16] Gellerstedt G, Li J, Eide I, Kleinert M, Barth T. Energy \& Fuels 2008; 22(6): 4240-4244. 